\title{
Medievalista
}

Online

12 | 2012

Número 12

\section{Morujão, Maria do Rosário Barbosa - A Sé de \\ Coimbra: A Instituição e a Chancelaria (1080-1318)}

\section{Maria João Oliveira e Silva}

\section{(2) OpenEdition}

\section{Journals}

\section{Edição electrónica}

URL: http://journals.openedition.org/medievalista/711

DOI: 10.4000/medievalista.711

ISSN: 1646-740X

Editora

Instituto de Estudos Medievais - FCSH-UNL

Edição impressa

Data de publição: 1 junho 2012

\section{Refêrencia eletrónica}

Maria João Oliveira e Silva, « Morujão, Maria do Rosário Barbosa - A Sé de Coimbra: A Instituição e a

Chancelaria (1080-1318) », Medievalista [Online], 12 | 2012, posto online no dia 19 fevereiro 2014, consultado o 22 setembro 2020. URL : http://journals.openedition.org/medievalista/711 ; DOI : https://doi.org/10.4000/medievalista.711

\section{(c) (7) (8)}

Mediavalista está licenciado com uma Licença Creative Commons - Atribuição-NãoComercial 4.0 Internacional. 
Título: Recensão

MORUJÃO, Maria do Rosário Barbosa - A Sé de Coimbra: A Instituição e a Chancelaria (1080-1318). Lisboa: Fundação Calouste Gulbenkian - Fundação para a Ciência e a Tecnologia (Ministério da Ciência, Tecnologia e Ensino Superior), 2010. 793 p. Autor(es): Maria João Oliveira e Silva Enquadramento Institucional: Centro de Estudos de História Religiosa - Universidade Católica Portuguesa Contacto: mariajoham@portugalmail.pt Fonte: Medievalista [Em linha]. №12, (Julho - Dezembro 2012). Dir. José Mattoso. Lisboa: IEM.

Disponível em: http://www2.fcsh.unl.pt/iem/medievalista/ ISSN: $1646-740 \mathrm{X}$

\section{Recensão}

MORUJÃ̃, Maria do Rosário Barbosa - A Sé de Coimbra: A Instituição e a Chancelaria (1080-1318). Lisboa: Fundação Calouste Gulbenkian Fundação para a Ciência e a Tecnologia (Ministério da Ciência, Tecnologia e Ensino Superior), 2010. 793 p.

\section{Maria João Oliveira e Silva}

O livro em epígrafe tem como base a dissertação de Doutoramento em História da Idade Média apresentada pela Autora na Faculdade de Letras da Universidade de Coimbra em 2005. Tratava-se, na altura da sua elaboração, de um tema praticamente por estudar em 
Portugal, uma vez que apenas se tinham realizado dois trabalhos de fundo dedicados às chancelarias particulares, nomeadamente à da Sé de Braga e à do mosteiro de Santa Cruz de Coimbra ${ }^{1}$, os quais são amiúde mencionados como contrapontos comparativos. No que à instituição coimbrã concerne, já vários autores lhe tinham dedicado atenção, sem que, no entanto, se tenha feito uma obra aprofundada sobre a mesma. Por essa razão, a Autora decidiu dividir o seu estudo em duas partes, definidas no próprio título: a primeira versando a Sé de Coimbra e a segunda a sua chancelaria. Quanto à cronologia escolhida, 1080-1318, corresponde ao período entre a restauração da Sé (com provas documentais do governo de D. Paterno) e o final do episcopado de D. Estêvão Eanes Brochardo (1303-1318), cuja experiência como chanceler de D. Dinis se haveria de reflectir na chancelaria episcopal.

A primeira parte, centrada no estudo da instituição eclesiástica, está dividida em quatro capítulos dedicados, respectivamente, à restauração e à organização da diocese coimbrã, aos seus bispos, à organização do cabido e, por último, ao governo da diocese. Apesar de bastante longa, em vários momentos a Autora assume que muitas vezes limitou a apresentação de mais dados, preterindo uma análise mais aprofundada face ao objectivo final do seu trabalho, ou seja, o estudo da chancelaria. Em geral, no primeiro capítulo segue trabalhos já realizados mas sempre que necessário questiona datas de episcopados e de documentos justificando plenamente as suas opções cronológicas. Usa também cartografia que, para além de por si só revelar muita informação, facilita a compreensão do que expõe. Mas é no segundo capítulo, dedicado aos prelados de Coimbra, que mais vezes corrige erros e confusões relativas a datas de episcopados. Apesar de não se sentir obrigada a citar todos os trabalhos já realizados sobre este assunto, nem de confirmar ou refutar os dados neles contidos, a verdade é que a Autora o faz com muita frequência ao longo do capítulo, mais uma vez provando as suas opções. Apresenta, sempre que possível, figuras com as subscrições episcopais. No entanto, talvez fosse aconselhável ter feito a transcrição das subscrições, atendendo, em especial, ao tipo de letra mas também à qualidade de algumas das reproduções, factos que dificultam a leitura das

\footnotetext{
${ }^{1}$ Ambas entretanto publicadas: CUNHA, Maria Cristina Almeida e - A Chancelaria Arquiepiscopal de Braga (1071-1244). Noia, Corunha Editorial Toxosoutos, 2005, e GOMES, Saul António - In Limine Conscriptionis. Documentos, chancelaria e cultura no Mosteiro de Santa Cruz de Coimbra (Séculos XII a XIV). Viseu: Centro de História da Sociedade e da Cultura, Palimage, 2007.
} 
mesmas por um público não especializado (nomeadamente a de D. Paterno escrita em visigótica de transição). Em relação às genealogias apresentadas, e justificado inteiramente o seu uso, note-se que é necessário chegar à Genealogia n³ (p.119) para se perceber o porquê de na legenda se identificar uma seta para "ligações hipotéticas" e outra para "ligações por bastardia", uma vez que nas genealogias números 1 (p.95) e 2 (p.104) estas setas surgem na legenda mas não são usadas, deixando o leitor na dúvida. No terceiro capítulo, focado na organização capitular, a Autora reafirma não ser sua intenção desenvolver o assunto, dando apenas "o primeiro passo do estudo" que o cabido coimbrão merece. Apesar disso, não deixa de analisar vários dados históricos, alguns dos quais narrados em documentos falsos ou interpolados que a Autora estuda do ponto de vista diplomático, de modo a sustentar a sua opinião em relação a esses mesmos documentos. No último e quarto capítulo, e apesar de novamente se referir o carácter sucinto e até lacunar dos dados apresentados, são estudadas as linhas gerais do governo da diocese ao longo do período em causa. A única dúvida prende-se com a distinção entre audiência e cúria episcopal que surgem, aqui, como uma mesma entidade, confusão que se mantém ao longo de todo o trabalho.

A segunda parte, relativa ao estudo da cancellaria episcopal, está dividida em três capítulos: o primeiro dedicado aos documentos da chancelaria, o segundo aos homens que a compunham, e o terceiro às práticas desta oficina gráfica.

O primeiro capítulo desta segunda parte é fulcral uma vez que nele são apresentados os conceitos basilares da obra, principalmente os de 'chancelaria' e de 'documento de chancelaria'. Com efeito, poucas vezes surge nos actos conimbricenses o termo cancellaria, bem como o de cancellarius, responsável máximo da chancelaria, facto que não invalida nem a existência da mesma nem a utilização do próprio termo (que se assume como conceito operacional). Quanto aos documentos de chancelaria a Autora optou por defini-los como sendo apenas os actos "emanados do bispo, do cabido e da audiência" (p.308). Dada esta definição, foram excluídos todos as actos destinados aos prelados, ao cabido, à Sé ou aos cónegos, como, por exemplo, doações ou vendas, uma vez que, a priori, e "sem o conhecimento prévio dos formulários e outras características (internas e externas)" (p.309), seria impossível saber, “com segurança", se também tinham sido da responsabilidade da chancelaria. De facto, não considerar a priori todos os documentos é um critério válido. No entanto, depois de conhecidos os formulários e 
as características (internas e externas) e expostos os critérios que classificam os actos como tendo sido produzidos na cancellaria de Coimbra, teria sido necessário analisar os que à partida foram excluídos e confirmar se foram, ou não, feitos na escrivaninha conimbricense. A exclusão a priori desses documentos impede, assim, o conhecimento mais aproximado da totalidade da produção da chancelaria, e, como consequência, do papel da mesma no panorama da produção escrita medieval portuguesa e europeia. E de facto a Autora, "para matizar as discrepâncias decorrentes do apertado critério" (p.320) que definiu, inclui, no estudo comparativo das médias de produção documental, não só os 506 actos que obedecem a esse critério, como também os 430 que foram excluídos.

O passo seguinte no estudo foi o de definir a tipologia dos 506 instrumentos seleccionados. A falta de designações nos próprios documentos dificultou essa tarefa e levou a que a Autora propusesse uma nova tipologia, "extensa e algo descritiva" mas que procura "conciliar o rigor histórico com o terminológico" (p.337). O conjunto documental foi dividido por cinco grandes categorias: actos relativos a assuntos de natureza económica, normas estatutárias e actos referentes à organização capitular, actos relativos à administração eclesiástica da diocese, actos relativos a assuntos judiciais e actos de natureza diversa, cada uma das quais com um número diverso de subcategorias, num total de 21. A Autora afirma que se trata de "uma extensa tipologia que traduz a riqueza e variedade dos escritos produzidos na chancelaria da catedral" (p.369). Mas conclui, igualmente, que somente dez das 21 subcategorias criadas possuem um número de actos superior à dezena. A Autora tem consciência de que a divisão "tem muito de artificial" e revela não ter sido fácil "integrar todos os documentos nas categorias e subcategorias propostas" (p.338). O exemplo que dá, relativo às sentenças, é paradigmático: de facto, e apesar de tratarem ora de assuntos económicos, ora de administração eclesiástica da diocese, foram sempre consideradas como sendo sentenças e englobadas nos actos relativos a assuntos judiciais e não nas categorias de cujo assunto tratam, ou seja, nos actos relativos a assuntos de natureza económica ou nos actos relativos à administração eclesiástica da diocese. Dado o exemplo, estranha-se que a mesma premissa não tenha sido aplicada, por exemplo, às confirmações ou às ratificações que acabaram por ser divididas pelas diversas categorias dependendo do assunto que nelas se trata. 
O segundo capítulo da segunda parte da obra é dedicado aos escribas da chancelaria, cujo estudo se revelou difícil dado que, para além das respectivas subscrições, poucas informações existem acerca dos mesmos. Agrava ainda mais a questão o facto de apenas cerca de $25 \%$ do total do corpus documental em análise ter sido subscrito. Contudo, os 71 "notários" estudados permitiram à Autora tirar várias conclusões acerca do quadro humano que compunha a chancelaria, nomeadamente sobre a evolução do mesmo em duas grandes fases diferenciadas, em especial, pela forma como os escribas se intitulam. Mas, tal como conclui a Autora, o estudo destes homens e os resultados obtidos seriam muito diferentes se o critério utilizado na selecção documental fosse outro, ou seja, se estivessem incluídos os actos dirigidos à Sé, aos bispos, etc. Tal facto é particularmente notório no que diz respeito ao número de documentos por eles produzidos e aos seus anos de actividade, chegando a passar, neste caso, de um para 30 anos de serviço, de 12 para 44 ou de 17 para 38. Em relação à produção de actos da chancelaria encontram-se exemplos de "notários" que produziram, por exemplo, um documento incluído no corpus mas de quem se conhecem outros 10 "extra corpus" (caso de Miguel Salomão), de três incluídos para 30 conhecidos (referente a Pedro Calvo) ou de um para 25 (relativo a Fernando, presbítero). Todos estes valores levaram a Autora a concluir que a possibilidade de parte dos documentos não seleccionados ter sido, efectivamente, produzida na chancelaria episcopal se via, pelo menos em parte, confirmada. Por essa razão, os dados apresentados deverão, ainda segundo a Autora, ser matizados porque podem não reflectir a realidade da chancelaria.

No terceiro capítulo é estudada a fase da conscriptio documental, nomeadamente do dictamen, da scriptio e da validatio. Em relação ao primeiro, é feita uma análise muito cuidada do ditado dos actos da chancelaria uma vez que não foram encontrados formulários para a redacção dos mesmos. Mas de novo a selecção documental parece comprometer, em parte, a análise das fórmulas da chancelaria, uma vez que foram excluídos alguns documentos, nomeadamente doações feitas à Sé, que incluem cláusulas que outros estudos provaram ser sui generis e, por isso, de grande interesse, em especial as arengas. 
Quanto à scriptio, a ausência de um estudo aprofundado é justificada, pela Autora, pelo maior interesse dado à análise diplomática mas também à existência de outros trabalhos de fundo sobre o tema ${ }^{2}$ e cujas conclusões, apesar das diferenças cronológicas, lhe pareceram válidas para a chancelaria de Coimbra. Contudo, e tal como conclui a Autora, nos séculos XIII e XIV a realidade gráfica é totalmente diferente da das centúrias anteriores já estudadas.

O estudo da validatio dos documentos da Sé revela-se de grande utilidade e interesse, principalmente no que ao estudo dos selos diz respeito. De facto, a documentação da chancelaria é prolixa no uso desta forma de validação que a Autora estuda acuradamente. Foi dada atenção não só às espécies sigilográficas em si, nomeadamente às episcopais, do cabido e da cúria, como também às matrizes (neste caso capitulares), e aos liames usados. A inclusão de várias reproduções de selos e dos próprios liames em muito contribui para a compreensão do estudo efectuado.

A obra termina com a apresentação através de quadros do corpus documental utilizado, e distribuído pelos respectivos outorgantes, ou seja, pelos bispos, pelo cabido e pela audiência episcopal. Estes quadros, que incluem a data, o sumário, a cota, a denominação coeva, a tipologia e o escriba de cada um dos documentos, são muito úteis para o conhecimento mais aprofundado e detalhado dos actos da chancelaria estudados.

É notório, ao longo de toda a obra, o cuidado da Autora em estabelecer ao máximo as relações entre a instituição (a sua história, os seus bispos e cabido, a sua organização e administração) e a chancelaria. De facto, o que se apresenta ao leitor, e que está plasmado logo na introdução, é o estudo da catedral em duas vertentes que só associadas a permitem conhecer verdadeiramente. Assim, a Autora procurou sempre perceber até que ponto a história da diocese e dos seus prelados, dividida em três grandes fases, provocou mudanças na própria chancelaria. E, por exemplo, com a morte

\footnotetext{
${ }^{2}$ Nomeadamente: SANTOS, Maria José Azevedo - Da Visigótica à Carolina. A escrita em Portugal de 882 a 1172. Lisboa: Fundação Calouste Gulbenkian / JNICT, 1994, e GUERRA, António Joaquim Ribeiro - Os diplomas privados em Portugal dos séculos IX a XII. Lisboa: Centro de História da Universidade de Lisboa, 2003.
} 
de D. Pedro Soares (último prelado da segunda fase) o quadro humano da chancelaria alterou-se, passando a ser constituído por escribas que primeiro se designam por tabelliones ou notarii, e, posteriormente, por scriptores jurati. Também a partir desse episcopado outras alterações se deram na oficina documental, nomeadamente, um forte aumento da produção escrita, uma crescente uniformização e simplificação dos formulários, assim como o incremento do uso do selo pendente como forma privilegiada de validação. Estes exemplos mostram que a chancelaria da Sé de Coimbra acompanhou o evoluir histórico da instituição, constituindo-se como um elemento crucial na construção da mesma.

\section{COMO CITAR ESTE ARTIGO}

\section{Referência electrónica:}

SILVA, Maria João Oliveira e - «Recensão» - "MORUJÃO, Maria do Rosário Barbosa - A Sé de Coimbra: A Instituição e a Chancelaria (1080-1318). Lisboa: Fundação Calouste Gulbenkian - Fundação para a Ciência e a Tecnologia (Ministério da Ciência, Tecnologia e Ensino Superior), 2010. 793 p”. Medievalista [Em linha]. №12, (Julho Dezembro 2012). [Consultado dd.mm.aaaa]. Disponível em http://www2.fcsh.unl.pt/iem/medievalista/MEDIEVALISTA12lsilva1209.html.

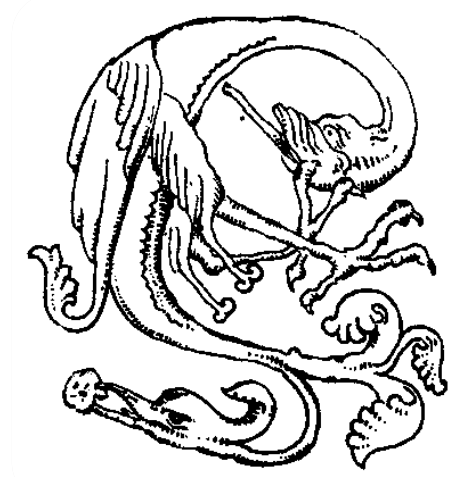

